\title{
Organ Measurements Specimen Type
}

National Cancer Institute

\section{Source}

National Cancer Institute. Organ Measurements Specimen Type. NCI Thesaurus. Code C119895.

The type of material sample taken from a biological entity for organ measurements. 